\title{
Cysts of the menisci of the knee
}

\author{
G. E. T. RAINE \\ F.R.C.S. \\ Senior Orthopaedic Registrar, \\ St George's Hospital, London, S.W.1 \\ and S.W. Metropolitan Regional Hospital Board
}

\section{Summary}

A review of a series of 249 consecutive meniscectomies reveals an overall incidence of cysts of the menisci of $20 \%$. Trauma in younger patients, and degeneration in older patients, appear to be causal factors.

\section{Introduction}

Cysts of the menisci, particularly of the lateral meniscus, are not uncommon, and most are easily diagnosed by the history and examination of the knee.

The first clinical description was by Ebner in 1904. Amongst the case reports in the literature are those of Becton \& Young (1965) who in a 20-year review found only twenty-eight cases. Bonnin in 1958 described twenty-nine cases to which he added a further twenty-one cases over an 8-year period. De Palma (1954) in a series of 507 knees found forty-eight with cystic degeneration, an incidence of $9 \%$, whilst Smillie (1970) in his massive series of meniscectomies, had 633 cases of cysts of the meniscus, an overall incidence of $8 \%$.

In our series there were fifty cysts in 249 cases, an incidence of $20 \%$.

\section{Material}

This series forms part of a larger series of 314 patients who underwent meniscectomy between 1963 and 1968 at three small hospitals in south-west London. The area supports a population of 250,000. There are no heavy industries but many light ones, and there are a large number of sporting clubs and organizations.

TABLe 1. Meniscectomies performed 1963-68

Meniscectomy for meniscus lesions

Total

\author{
L. C. L. GONET \\ F.R.C.S.
}

\author{
Consultant Orthopaedic Surgeon, \\ Putney Hospital (Westminster Hospital \\ Teaching Group), London, S.W.15
}

Two hundred and forty-nine of these patients underwent meniscectomy as a planned procedure for lesions of the lateral or medial meniscus, and are reviewed elsewhere (Gonet \& Raine, 1972), and of these, fifty were found to have cysts of the menisci. The majority of operations were performed by one of us (L.C.L.G.). In each case the cyst and meniscus were excised together or separately. There were no recurrences.

\section{Presentation}

The majority of cases presented as a lump near the knee joint line; in three cases medial, thirtythree lateral. The lump might be as large as $5 \mathrm{~cm}$ diameter, and cysts which were barely palpable in size when seen initially enlarged steadily in 6 or 9 months.

TABle 2. Mode of presentation in fifty cases

\begin{tabular}{lr}
\hline Lump & 36 \\
Pain & 9 \\
Operative finding & 5 \\
$\quad$ Total & 50 \\
\hline
\end{tabular}

On the lateral side the cysts appeared at the classic location of the middle third of the meniscus, and were firm or hard in consistency. All cases reviewed were operated on and the diagnosis confirmed operatively and histologically.

On the medial side of the knee the three cysts which presented clinically were softer in consistency.

\section{Pain}

Nine patients presented with pain as the initial symptom. On questioning, almost all patients had pain at some stage. This pain may be confined to the cyst, or spread up and down the leg. Pain in the outer side of the knee, inability to get comfortable in bed, and a dull ache at night, were symptoms described by many patients. 
TABLE 3. Meniscectomy review 196368 inclusive

\begin{tabular}{|c|c|c|c|}
\hline & Male & Female & Total \\
\hline \multicolumn{4}{|l|}{ Medial } \\
\hline Cyst in presence of intact meniscus & 2 & 2 & 4 \\
\hline Cyst in presence of torn meniscus & 2 & 1 & 3 \\
\hline Torn meniscus & 122 & 25 & 147 \\
\hline $\begin{array}{l}\text { Meniscus intact though not necessarily } \\
\text { normal }\end{array}$ & 21 & 7 & 28 \\
\hline Total & 147 & 35 & 182 \\
\hline \multicolumn{4}{|l|}{ Lateral } \\
\hline Cyst in presence of intact meniscus & 15 & 17 & 32 \\
\hline Cyst in presence of torn meniscus & 4 & 7 & 11 \\
\hline Torn meniscus & 11 & 4 & 15 \\
\hline $\begin{array}{l}\text { Meniscus intact though not necessarily } \\
\text { normal }\end{array}$ & 6 & 3 & 9 \\
\hline Total & 36 & 31 & 67 \\
\hline
\end{tabular}

There were 249 meniscectomies in 244 patients - 186 male, 63 female. Average age 36 years.

TABLE 4. Cysts of the menisci (lateral and medial combined)

\begin{tabular}{lccc}
\hline & Male & Female & Total \\
\hline Cyst + intact meniscus & 17 & 19 & 36 \\
Cyst - torn meniscus & 6 & 8 & 14 \\
Total & 23 & 27 & 50 \\
\hline
\end{tabular}

Average age 36 years.

\section{Operative}

In five cases, of which four involved the medial meniscus, the cysts were entirely intrameniscal, in association with an intact meniscus. These were visible to the naked eye.

\section{Analysis}

Tables 3 and 4 and Figs. 1 and 2 present a summary of our findings.

\section{Incidence}

Sixty-seven lateral meniscectomies were performed in this series and in forty-three a cyst was present. This high incidence of two out of three is triple the incidence in Smillie's and De Palma's series. The presence of fifty cysts in 249 meniscectomies is also more than double that of the other series.

\section{Age}

Figure 1 shows that the decade 20-29 is the peak period for cystic change to manifest itself, and that there is then a definite but declining incidence over the next 40 years. Figure 2 shows this peak to be in males. In every other age-group, females equal or outnumber males. In this series therefore, cystic change is a complaint of young males and of women of all ages. The large number of females brings up the ratio coming to meniscectomy to 1 in 3 (Table 3 ).

The average age of patients with cysts is identical with that for the series as a whole.

\section{Trauma}

Many patients gave a history of direct trauma to the knee. No figures are recorded in this series to

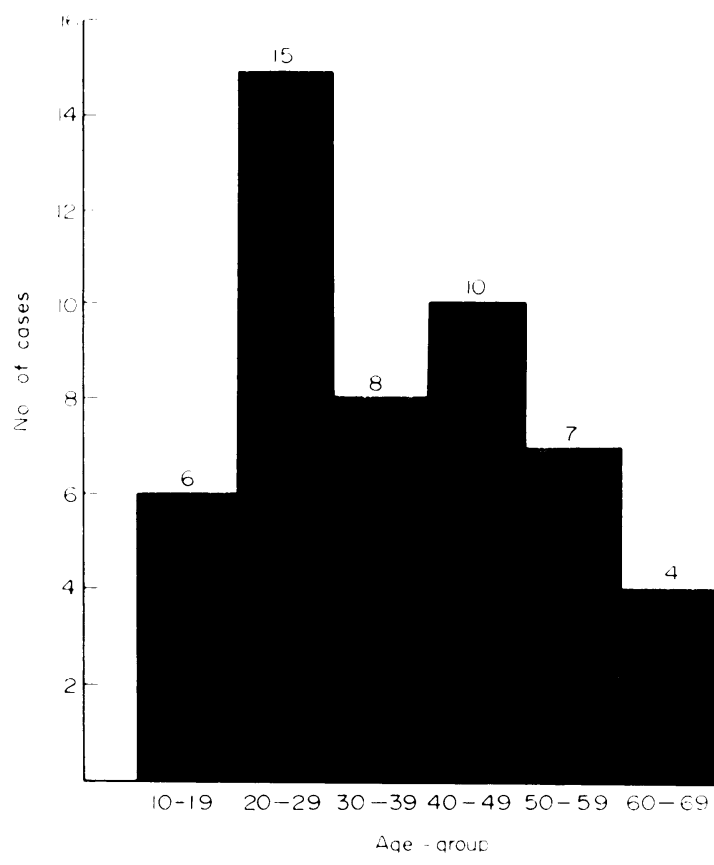

Fig. I. Meniscal cysts. Incidence hy decades. 


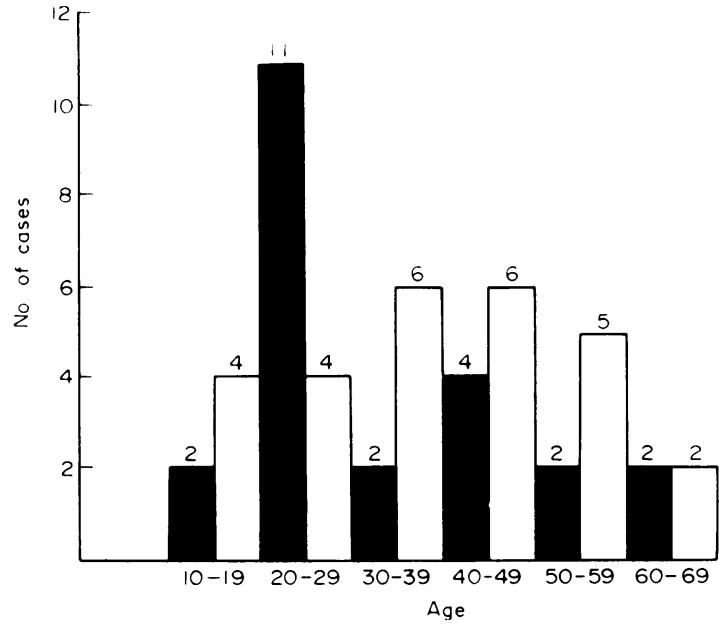

FIG. 2. Meniscal cysts. Incidence by decades (male and female compared). Closed columns, males; open columns, females.

show a direct relationship with the subsequent development of a cyst.

However, fourteen of fifty $(28 \%)$ of the cysts excised were in association with a torn meniscus, and this infers that a twisting injury is a cause of cyst formation.

\section{Discussion and conclusions}

The maximal incidence in young males of the athletic age-group fits with similar findings by Smillie. This suggests that trauma is an importat factor in the pathogenesis of cysts. It has not been extablished whether menisci tear more easily because they contain a cyst, or whether the cyst is the result of repeated minor trauma producing a cleavage lesion in the substance of the meniscus. Bonnin (1952) suggests that the presence of a cyst adjacent to the periphery of a normal lateral meniscus tethers it (in the way that a medial meniscus is tethered to the medial capsule) and that this leads to increased susceptibility to tearing in response to a twisting injury.
The overall preponderance of women in this series is of interest. Half of these were aged 40 or over, and the usual location of the cyst was on the lateral side. It is felt that these cysts are of degenerative origin. Apart from repeated trauma, the outer side of the knee is liable to abduction injury. Repeated minor trauma may occur in obese persons. Housewives also squat, bend, and kneel. As a result, a split in the periphery of the meniscus may be filled with haematoma and subsequently the cavity and contents undergo mucoid degeneration. The microscopic anatomy of these cysts is interpreted as a split in fibrous tissue. They are lined by compressed fibroblasts, not by epithelium, and they do not communicate with the knee joint cavity. In time, repeated shearing stresses cause the cyst to enlarge and to be extruded from the meniscus and become palpable beneath the capsule.

Finally, the increase in numbers in this series is probably due to more clinical awareness of the condition, particularly in women.

\section{Acknowledgments}

We wish to thank the South-West Metropolitan Regional Hospital Board Decentralized Research Committee for a grant towards this study. We are grateful for the help of the clerical and physiotherapy staffs of Battersea and Putney Hospitals

\section{References}

Becton, J.L. \& Young, H.H. (1965) Cysts of the semilunar cartilages of the knee. Archives of Surgery, 90, 708.

BonNin, J.G. (1952) Cysts of the semilunar cartilages of the knee joint. British Journal of Surgery, 40, 558.

Bristow, W.R. (1928) The Robert Jones Birthday Volume, p. 269. Oxford University Press, London.

De Palma, A.F. (1954) Diseases of the Knee, 3rd edn. Lippincott, Philadelphia.

EBNER, A. (1904) Münchener medizinische Wochenschrift, 51, 1737.

Gallo, G.A. \& Bryan, R.S. (1968) Cysts of the semilunar cartilages. American Journal of Surgery, 116, 65.

GONET, L.C.L. \& RAINE, G.E.T. (1972) Meniscectomy-a review of 249 cases. Postgraduate Medical Journal, 48, 33.

Gristina, A.G. \& Wilson, P.D. (1964) Popliteal cysts in adults and children. Archives of Surgery, 88, 357.

Smillie, I.S. (1970) Injuries of the Knee Joint, 4th edn, Chap. 4 and 5 . Livingstone, Edinburgh. 